\title{
Reliability Analysis of Pre-stressed Concrete Continuous Girder Bridges using Cantilever Construction on JTG D60-2015 and AASHTO LRFD-2012
}

\author{
C.H. LOU,F.H. DONG \\ Department of Bridge Engineering in Chang'an Univerisity, Shaanxi Xi'an, China \\ Department of Bridge Engineering in Tongji Univerisity, Shanghai, China
}

KEYWORD: Pre-stressed concrete; Girder bridge; Cantilever construction; Service stage; Reliability index

ABSTRACT: The object of this paper analyzes the reliability level of pre-stressed concrete continuous girder bridges designed with the Chinese codes including the code for design of highway reinforced concrete and pre-stressed concrete bridges and culverts of AASHTO LRFD2012 and JTG D60-2015 using cantilever construction method. Typical cross-sections used in the example bridge are considered at service stage. Load and resistance parameters are treated as random variables. The statistical parameters are based on the available literature, test data and survey results. Reliability indices are calculated by iterations using the first-order second-moment method. The calculated results indicate that the reliability indices on the code of AASHTO LRFD2012 vary considerably to the code of JTG D60-2015. And it could provide the references for the reinforcement of old bridges and the design of new bridges using the cantilever construction.

\section{INTRODUCTION}

Because of the structure stress performance good, deformation small, the expansion joint to be few slightly, the driving smooth and comfortable, the modeling succinct and artistic, the maintenance resilience is small, earthquake resistance ability strong and so on, the pre-stressed concrete continuous girder bridge becomes one of the richest competitive power main bridges. In the great span pre-stressed concrete continuous girder bridges which already completed in our country, the majority were constructed by the cantilever construction. This is because we have the mature experience on the cantilever construction, and the cantilever casting pre-stressed concrete continuous bridges as a kind of bridges taking the non-support construction are advantageous to be constructed at the navigation rivers, the remote mountain canyon and the urban grade separation.

So far, to the authors' knowledge, the reliability analysis has not been applied to the pre-stressed concrete continuous girder bridges using cantilever construction method. This study focuses on analyzing the reliability indices of pre-stressed concrete continuous girder bridges designed with the Chinese code for design of highway reinforced concrete and pre-stressed concrete bridges and culverts of AASHTO LRFD-2012 (Americans association of State Highway and Transportation Officials,2012) and JTG D60-2015 (Ministry of Transport of the People's Republic of China, 2015) using cantilever construction at the service stage.

\section{BASIC INFORMATION OF THE BRIDGE}

The bridge, which is a pre-stressed concrete post-tensioned continuous girder bridge with the span of $30 m+45 m+30 m$ (Figure.1), is constructed by cantilever construction method in the highway, and its total length is $105 \mathrm{~m}$. The length of the center of the side pier and the beam-ends is $0.58 \mathrm{~m}$, in addition, the length of the side span is $29.4 \mathrm{~m}$. The geometry of girder of the middle span and the top of pile is shown in Figure.2, in which all dimensions are in centimeters.

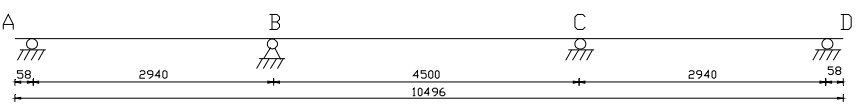

Figure.1 Calculation mode of the bridge 


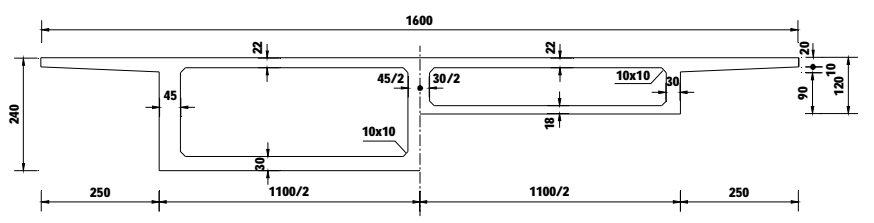

$1 / 2$ middle span $\quad 1 / 2$ top of pile

Figure.2 Girder geometry (unit: $\mathrm{cm}$ )

\section{FINITE ELEMENT MODELING}

The finite element method adopted in this study is based on the procedure developed by MIDAS IT Co. (MIDAS IT Co., 2001) for the deterministic analysis of pre-stressed concrete bridge using cantilever construction during its service stage. The arbitrary plane geometry and variable cross section can be modelled as an assembly of finite elements interconnected at nodal points. The analytical model consists of 75 nodes and 74 elements. The 75 nodes were located at segment joints along the centroidal axis of the box girder. The 74 beam elements were used to model the box girder shown in Fig.3, where only the cross-section numbers of one to eight are located.

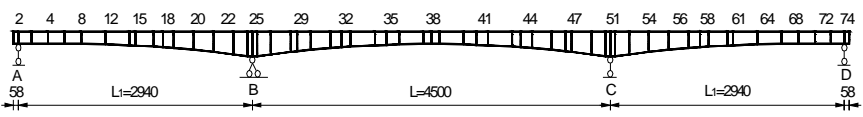

Figure.3 Elements meshing

\section{LOAD MODEL}

The major load components for highway bridges are dead load, live load, dynamic load, environment loads (temperature, wind, earthquake), and other loads (collision, braking). In this study, only the first three are considered, the load models are based on the available statistical data, surveys, inspection reports, and analytical simulations. The load variation is described by cumulative distribution function (CDF), mean value or bias factor (ration of mean to nominal value), and coefficient of variation.

Dead load is the gravity load due to the self- weight of structural and non-structural elements (pre-stressing force in this study) permanently connected to the bridge. For asphalt wearing surface it is assumed that mean thickness is $80 \mathrm{~mm}$. In concrete structures, pre-stressed effects are generally considered as a force being applied to the structure. Live load covers a range of forces produced by vehicles moving on the bridge. Truck surveys indicate that it is strongly site-specific, from geographical region to region, and even within a region. Both static and dynamic (impact load) effects of live load are considered in this study.

The load statistical parameters (Ministry of Construction of the People's Republic of China, 1999; Chaw K W, 2007) on codes of AASHTO LRFD-2012 and JTG D60-2015 for the example bridge are shown in Table.1.

Table.1 Load statistical parameters on codes of JTG D62-2004 and AASHTO LRFD-2012

\begin{tabular}{|c|c|c|c|c|c|c|c|}
\hline & \multirow{2}{*}{$\begin{array}{l}\text { Distributi } \\
\text { on }\end{array}$} & \multicolumn{2}{|c|}{ Mean } & \multicolumn{2}{|c|}{ Standard deviation } & \multicolumn{2}{|c|}{ Coefficients of variation } \\
\hline & & LRFD-2012 & D $60-2015$ & LRFD-2012 & D60-2015 & LRFD-2012 & D60-2015 \\
\hline Deadload & Normal & 1.05 & 1.0148 & 0.0105 & 0.0437 & 0.1 & 0.0431 \\
\hline Prestress & Normal & \multicolumn{2}{|c|}{1} & \multicolumn{2}{|c|}{0.04} & \multicolumn{2}{|c|}{0.04} \\
\hline Live load & Extreme I & 1 & 0.6684 & 0.12 & 0.2493 & 0.12 & 0.3730 \\
\hline Impact load & Extreme I & 1 & 0.6684 & 0.12 & 0.2493 & 0.12 & 0.3730 \\
\hline
\end{tabular}

\section{RESISTANCE MODEL}

Resistance is a variable representing the load carrying capacity. It can be affected by uncertainties in strength of materials, dimensions and analysis. The type of distribution is based on observed shape of CDFs for presenting steel and concrete. Resistance is considered as a product of three 
factors representing strength of materials, dimensions and analysis. Therefore, it is log-normally distributed (Rosignoli, 2002).

The minimum required resistance of flexural capacity at the service stage is defined by the Chinese code. The flexural capacity statistics on codes of AASHTO LRFD-2012 and JTG D602015 for the example bridge are shown in Table.2.

Table.2 Flexural capacity statistics for the example bridge

\begin{tabular}{cccc}
\hline & Distribution & Mean & Coefficient of variation \\
\hline D60-2015 & log-normal & 1.2262 & 0.1414 \\
LRFD-2012 & log-normal & 1.05 & 0.075 \\
\hline
\end{tabular}

\section{LIMIT STATE FUNCTION}

Load and resistance are treated as random variables. The statistical models are based on the available literature. Ultimate limit state of flexural capacity (bending moment) at the service stage and limit stress of cross-sections at the construction stage are considered respectively in this study with the following limit state function,

$g=R-S$

where $\mathrm{R}$ is the resistance or load-carrying capacity, and $S$ is the total load effect.

The total load is a sum of several components, $S=\mathrm{D}+\mathrm{L}+\mathrm{I}+\mathrm{P}$ for flexural capacity at the service stage, where $\mathrm{D}$ is the dead load effect, and $\mathrm{L}$ is the live load effect including impact, and $\mathrm{P}$ is prestressing load.

\section{RELIABILITY THEORY}

In a probabilistic procedure, the effect $S$ applied to a structural element and $R$, the resistance variable, are described as being random, since their values are not perfectly known. If the verification of the criterion related to the limit state results in equality:

$g=R \leqslant S$

with the component's failure being related to exceeding this limit state, then the probability $P_{F}$ of the event $(R-S)$ will characterize the component's level of reliability in relation to the considered limit state:

$$
P_{F}=P(R<S)
$$

Very few distributions of $R$ and $S$ lead to a direct integration of the convolution integral. The simplest example introduces two normal variables with respective means and variables. Since the difference of two normal variables is a normal variable, the safety margin $M=R-S$ is a random variable with a mean and a variance. The failure probability is then given by:

$P_{F}=P(M<0)=F_{M}(0)$

when $F_{M}(9$ is the cumulative probability function of variable $M$. Since we are dealing with a normal variable, we obtain:

$$
\begin{aligned}
P_{F} & =F_{M}(0) \\
& =\Phi\left(\frac{0-m_{M}}{\sigma_{M}}\right) \\
& =\Phi\left(-\frac{m_{R}-m_{S}}{\sqrt{\sigma_{R}^{2}+\sigma_{S}^{2}}}\right)
\end{aligned}
$$

with $\Phi(\bullet)$ as cumulative probability function of a standard normal variable (zero mean and unitary standard deviation). The term: 


$$
\beta=\frac{m_{M}}{\sigma_{M}}=\frac{m_{R}-m_{S}}{\sqrt{\sigma_{R}^{2}+\sigma_{S}^{2}}}
$$

is called the reliability index.

\section{RELIABILITY ANALYSIS}

Reliability analysis is performed for pre-stressed concrete bridge girders designed according to the considered codes. The reliability index, $\beta$, is defined as a function of probability of failure, $P_{F}$, $\beta=-\Phi^{-1}\left(P_{F}\right)$

An iterative procedure is used calculate the reliability index as described by Ming Zhang (Zhang, 2009).With the above-mentioned assumptions and statistical parameters and using the procedure for reliability analysis, reliability indices of the cross-sections at the service stage are shown in Table.3. Reliability indices on codes of AASHTO LRFD-2012 and JTG D60-2015.

Table.2 reliability indices on codes of AAS HTO LRFD-2012 and JTG D60-2015

\begin{tabular}{ccccccccccc}
\hline \multicolumn{2}{c}{ Cross-section number } & 2 & 8 & 15 & 20 & 25 & 32 \\
\hline \multicolumn{2}{c}{ Cross-section location } & $\mathrm{A}$ & $\mathrm{L}_{1} / 4$ & $\mathrm{~L}_{1} / 2$ & $3 \mathrm{~L}_{1} / 4$ & $\mathrm{~B}$ & $\mathrm{~L} / 4$ & $\mathrm{~L} / 2$ \\
\hline \multirow{2}{*}{ Reliability indices } & D60-2015 & 10.3325 & 7.5126 & 7.9755 & 7.8864 & 6.7739 & 8.2155 & 6.8763 \\
& LRFD-2012 & 9.8726 & 7.3274 & 7.6423 & 8.4578 & 7.2265 & 8.4377 & 7.2153 \\
\hline
\end{tabular}

\section{SUMMARY}

Subject to the limitations of the assumptions and parameters adopted in the study, the following conclusions can be obtained:

(1) The calculated reliability indices results of cross-section number at $A, L_{1} / 4$ and $L_{1} / 2$ in the code of AASHTO LRFD-2012 are less than that of JTG D60-2015.

(2) The calculated reliability indices results of cross-section number at $3 \mathrm{~L}_{1} / 4, \mathrm{~B}, \mathrm{~L} / 4$ and $\mathrm{L} / 2$ in the code of AASHTO LRFD-2012 are larger than that of JTG D60-2015.

\section{ACKNOWLEDGEMENTS}

The writers are grateful for the assistance of undergraduate and graduate students in this work. These supports are gratefully acknowledged.

\section{REFERENCES}

[1] AASHTO LRFD Bridge Design Specifications.2012. Americans association of State Highway and Transportation Officials, Washington, DC.

[2] Ministry of Transport of the People's Republic of China. 2015. General Code for Design Highway Bridges and Culverts (JTG D60-2015). Beijing: People's Communication Press.

[3] MIDAS IT Co. 2001. MIDAS Manual, Seoul, Korea.

[4] Ministry of Construction of the People's Republic of China. 1999. Unified Standard for Reliability Design of Highway Engineering Structures (GB/T 50283-1999). Beijing: China Planning Press.

[5] Chaw K W. 2007. Reliability and Performance-based Design by Artificial Neural Network [J]. Advances in Engineering Software. 8:145-149.

[6] Rosignoli, Marco. 2002. Bridge Launching. Thomas Telford Ltd, Parma, Italy.

[7] Ming Zhang. 2009. Structure Reliability Analysis-method and Procedures. Beijing: Science Press. 